
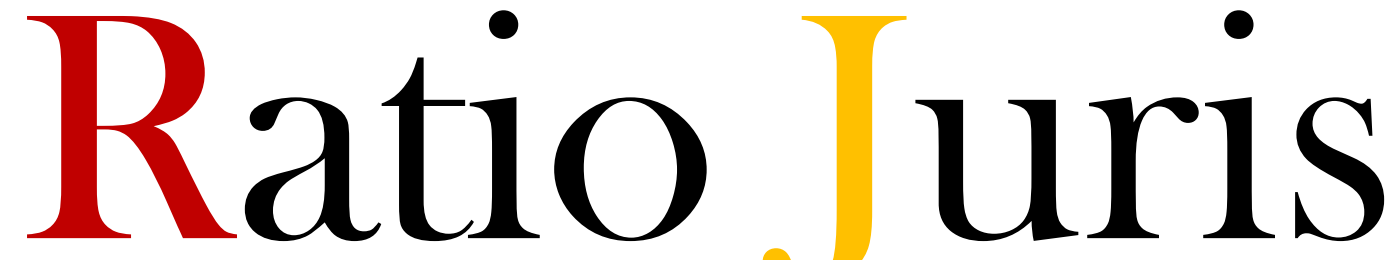

Publicación Semestral de la Facultad de Derecho UNIVERSIDAD AUTÓNOMA LATINOAMERICANA

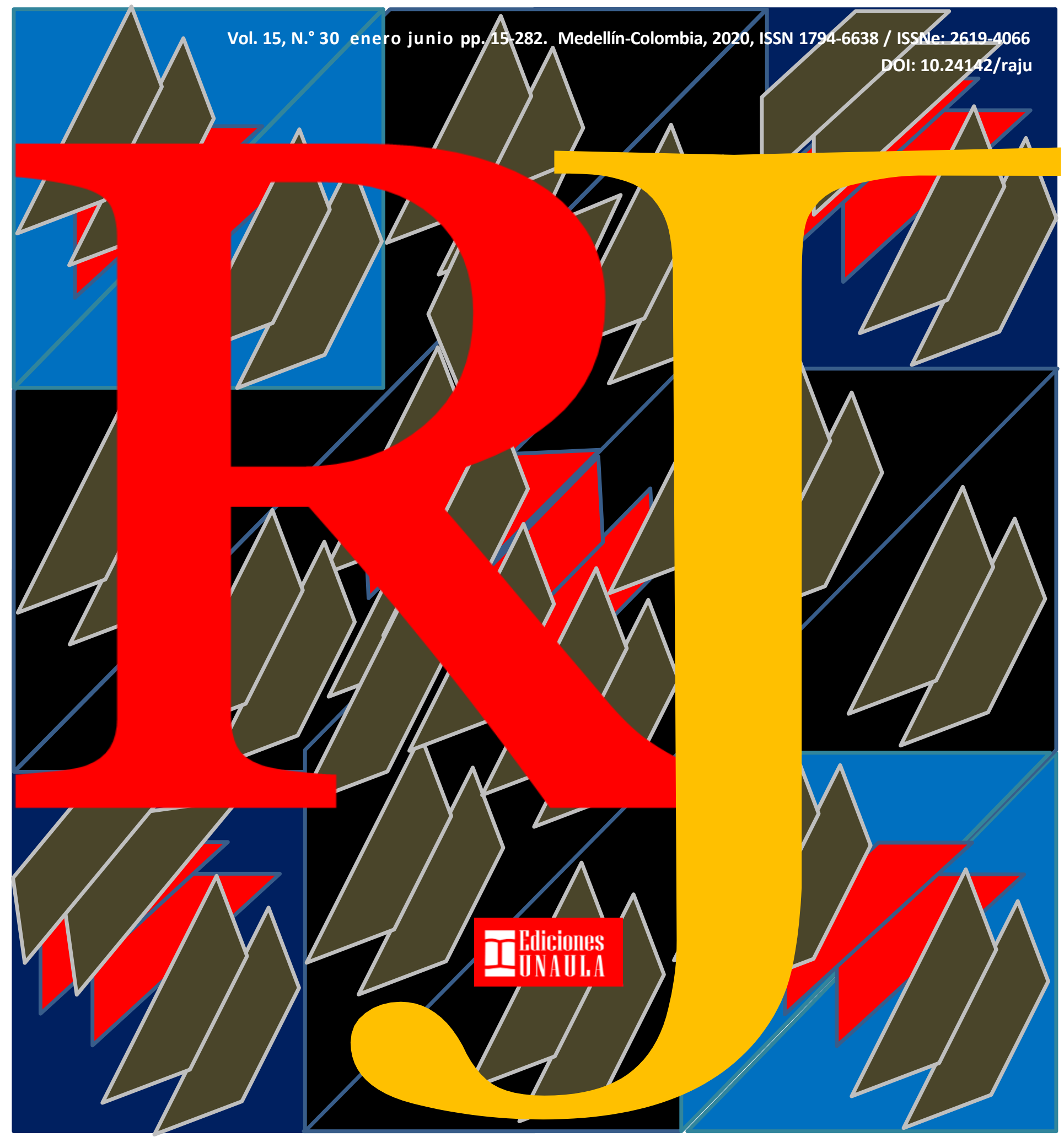




\title{
La psicología del poder: una reflexión en tiempos de pandemia
}

\author{
The psychology of power: a reflection in times of pandemic
}

\section{A psicologia do poder: uma reflexão em tempos de pandemia}

\author{
Anyuli Margarita-Ospina ${ }^{1}$ \\ Recibido: 20 de marzo de 2020 - Aceptado: 20 de abril de 2020 - Publicado: 30 de junio de 2020 \\ DOI: $10.24142 /$ raju.v15n30a15
}

\section{Resumen:}

Actualmente, genera incertidumbre la devastación que ha causado en las diferentes esferas de la humanidad la reciente aparición de una nueva enfermedad denominada COVID 19, declarada como pandemia en el mes de marzo del año en curso por la organización mundial de la salud. Una pandemia en tiempos de acelerado desarrollo económico, científico y tecnológico. No obstante, una pandemia en tiempos donde la adaptación de las sociedades y los cambios que ésta implica no es sólo una necesidad sino un factor determinante en la superación de la crisis actual, llevando a un cambio de paradigmas. En este sentido, la intención de esta reflexión es resaltar la utilización de una psicología del poder donde su finalidad es influenciar a las personas y pretender un mundo más justo y equilibrado. Un sistema donde las personas trasciendan los intereses individuales y se enfoquen en la construcción y fortalecimiento de un Estado en pro del bienestar colectivo.

Palabras Clave: Psicología del poder; principio del placer; solidaridad; bienestar; igualdad.

\begin{abstract}
Currently, the devastation caused by the recent appearance of a new disease called COVID 19, declared a pandemic in March of this year by the world health organization, has created uncertainty. A pandemic in times of accelerated economic, scientific and technological development. However, a pandemic in

${ }^{1}$ Psicóloga, Estudiante de Maestría en derecho Universidad Católica Luis Amigo, Orcid: https://orcid.org/00000002-1344-4597 anyimar99@yahoo.es
\end{abstract}


times when the adaptation of societies and the changes that this implies is not only a necessity but a determining factor in overcoming the current crisis, leading to a paradigm shift. In this sense, the intention of this reflection is to highlight the use of a psychology of power where its purpose is to influence people and seek a more just and balanced world. A system where people transcend individual interests and focus on the construction and strengthening of a State in favor of collective wellbeing.

Keywords: Psychology of power; pleasure principle; solidarity; wellness; equality.

\section{Resumo:}

Atualmente, a devastação causada pelo recente aparecimento de uma nova doença chamada COVID 19, declarada pandemia em março deste ano pela organização mundial de saúde, criou incertezas. Uma pandemia em tempos de desenvolvimento econômico, científico e tecnológico acelerado. No entanto, uma pandemia nos tempos em que a adaptação das sociedades e as mudanças que isso implica não são apenas uma necessidade, mas um fator determinante para superar a crise atual, levando a uma mudança de paradigma. Nesse sentido, a intenção dessa reflexão é destacar o uso de uma psicologia do poder, cujo objetivo é influenciar as pessoas e buscar um mundo mais justo e equilibrado. Um sistema em que as pessoas transcendem os interesses individuais e se concentram na construção e fortalecimento de um Estado em favor do bem-estar coletivo.

\section{Introducción}

La enfermedad por COVID-19 desde su aparición en el mes de diciembre del 2019 hasta la fecha actual, acumula un poco más de 3 millones de personas infectadas y ha causado alrededor de 230.000 muertes (OMS, 2020). Sin embargo, el tema que se quiere plantear es una discusión no desde los paradigmas científicos y biomédicos que implica la actual crisis mundial, sino al contrario desde los paradigmas sociales y psicológicos. Esta reflexión, tampoco pretende hacer una crítica al sistema capitalista y a los tipos de gobierno, temas que se han visibilizado con mayor fuerza durante la pandemia; y aunque sin lugar a duda tienen gran relevancia actualmente; son temas ampliamente discutidos y analizados por diferentes expertos y áreas del conocimiento.

La actual pandemia, delimita un tiempo de crisis, donde se hace necesario que todas las partes que conforman un Estado, se movilice y salga del estatus quo, que sus principios estén basados en pensamientos, comportamientos y acciones dirigidos a la renuncia del principio de placer, recurriendo al valor de la solidaridad, la igualdad de oportunidades, la inclusión y cohesión social. Comportamientos que delimitan el concepto de solidaridad teniendo en cuenta dos variables que son: la crisis y la temporalidad, evitando el empuje desenfrenado a un asistencialismo que dificulte los mecanismos propios para un adecuado desarrollo. 
Retomar una psicología del poder, ilustrándolo de manera concisa en sus aportes con relación al tema que se pretende abordar, y para ello se retoman alguno de los argumentos que plantea Le Bon, en su texto la Psicología de las masas, los postulados de Marx (1850) basados en textos como: la lucha de clases en Francia de 1848 a 1850 y manuscritos del partido comunista, (2011) las teorías de Freud en sus obras: Mas allá del principio del placer, y psicología y de las masas. El propósito de plantear las ideas de estos tres autores tiene como finalidad el logro de un inicio al cambio de mentalidad y motivando a los seres humanos, principalmente sus dirigentes, recurran a potenciar sus valores y virtudes, acudiendo a su ética personal, a su poder e investidura para promover comportamientos sociales que beneficien a toda una colectividad.

\section{La psicología del poder}

A continuación, se plantea una breve revisión de algunas posturas que, a través de la historia, han realizado aportes significativos para fortalecer los modelos políticos, sociales y económicos, con el objetivo principal de buscar un equilibrio social. Quiero referirme a una psicología del poder, que sin llamarla así propiamente en su propuesta escrita se puede inferir que Le Bon, al referirse que los seres humanos pueden ser controlados a través de la identidad de grupo, sistema de creencias y estructuras sociales, Los cuales se han utilizado por líderes que han ejercido el poder en momentos históricos. También mi preferencia es retomar algunas ideas de Karl Marx, siendo un apoyo teórico su defensa por lograr un orden más humano, la igualdad económica y la justicia social y por último mencionar el principio de placer, que, según Freud, el hombre es regido por instintos y deseos (1992).

La psicología del poder ha existido desde tiempos históricos y se podría decir que ha sido uno de los mecanismos de control más poderosos que ha utilizado un líder político para someter, alienar y lograr que las personas se convenzan de que se está haciendo lo mejor por ellas y que el orden establecido es el que deben asumir sin protestar porque es el que les conviene.

De acuerdo a lo planteado quiero hacer referencia por ejemplo a los líderes que promovieron la II guerra mundial quienes visibilizaron sus armas más poderosas para ejercer un mayor control, las cuales fueron: el infundir miedo, incertidumbre, y sugestión agregándole a su tiranía de poder, la privación de alimento, abrigo y exclusión social; En la actualidad existen armas de control parecidas, como por ejemplo los medios de comunicación con una multitud mensajes, nos atemorizan o nos llevan a terminar haciendo lo que otros quieren sin utilizar las barreras físicas. Para mencionar el predominio de una psicología del poder, esta Le Bon, quien basa su teoría en la psicología de las masas siendo varios de sus argumentos estrategias que abren caminos para ejercer un control para lograr lo que se desea. Haciendo alusión a algunos de sus postulados se observa que: el primero se refiere a la 
sugestionabilidad y credulidad de las masas, lo que conlleva al logro de los comportamientos deseados, el segundo lo nombra la ley de la unidad mental donde se pierde o fusiona la individualidad, y para finalizar nombra que: conocer el arte de impresionar la imaginación de las masas es conocer el arte de gobernar.

\section{Volver a Marx}

Como se puede analizar estos aspectos han logrado dominar por largos periodos de tiempo muchas sociedades, pero deja un cuestionamiento y es la temporalidad, lo que hace que pierda fuerza y se afirme el concepto de Le Bon con relación a que la masa no piensa por sí misma, ni tiene su propia identidad (2004).

Es por esto por lo que, con relación a los postulados anteriores, sería interesante si consolidaran con las premisas que propone Marx, quien presenta una tendencia por, a dignificación humana y aunque su defensa se enfocó en la lucha por la igualdad de clases sociales, modificar el orden social y político, su finalidad estaba en buscar un orden social más humano, la igualdad económica y extinguir la premisa: la explotación del hombre por el hombre. Esta mirada conlleva a pensar en una psicología del poder materializada en lo que constituye el desarrollo social en busca de un equilibrio a través de la renuncia del estatus quo que se pretende sostener en la mayoría de las sociedades actuales. Y si se observa el panorama del efecto pandémico, se visibilizan las estrategias de algunos gobernantes que al parecer manifiestan una lucha entre el deber ético en el ejercicio del poder, y la protección de sus propios intereses.

\section{Ceder al principio de placer}

Es importante develar que la crisis se ha agudizado en los varios ámbitos, reduciendo en muchos seres humanos, el sentido cooperativo, y el valor de la solidaridad, los cuales se ven nublados, por el exagerado interés y ambición de quienes tiene el poder político y económico, quienes no desean salir de su zona de confort y cediendo a su principio de placer, como lo expresa Freud en sus textos planteando una teoría de las pulsiones, mencionando que el ser humano se enfrenta a dos posibilidades: una egoísta o primitiva y la otra colectiva dirigida hacia el otro mediada por la cultura, esta afirmación conlleva a pensar que para lograr el bienestar común, se debe ceder parte de la felicidad individual. Siendo así, se puede deducir que el ser humano puede desarrollar conductas solidarias que trasciendan el pensar solo en sí mismo, cediendo solo a sus deseos, y aunque estas actitudes, comportamientos, o valores se instauren en la etapa infantil, es posible pensar que por medio de una Psicología del poder es posible modificar y desarrollar comportamientos deseables en una colectividad, y principalmente en situaciones críticas donde están implicadas no solo las condiciones para preservar la vida en este caso de pandemia, tratando de evitar el contagio, y que también están atravesados por las posibilidades de poder subsistir supliendo las necesidades básicas. 


\section{Concluyendo}

Con base a estas conductas de solidaridad, se buscaría poner al servicio recursos económicos, recursos humanos, saberes, unión de voluntades, servicios, todo esto sin ánimo de lucro, donde los dirigentes del Estado se apropiaran de una psicología del poder no para alienar, no para sostener el conformismo de sus seguidores, no para atemorizar por los medios de comunicación, no para privilegiar a los más poderosos, sino para sacar un proyecto de bienestar y equilibrio social, donde no hallan móviles ocultos, desviación de recursos, ni peculado, donde la Institucionalidad devele su transparencia y no se refugie en una falsa identidad ,y que el Estado cumpla uno de los objetivos principales: promover la prosperidad y el bienestar común, materializando esto, se podrá confiar y asumir la firme creencia que generando un cambio de paradigma, nada volverá a ser igual al finalizar la pandemia.

A través de la historia los seres humanos se han preocupado porque sus decisiones y elecciones sean autónomas, libres de coacción y control, sin darse cuenta de que ya se ha estado por milésima de años en una situación de contagio de comportamientos de conformismo político y social. Y en este sentido quizás las teorías de Le Bon, (2004). han adquirido la fuerza para lograrlo, pero en un sentido poco favorable, teniendo en cuenta que las teorías y postulados se pueden ubicar o para realizar grandes y significativas acciones en favor de la humanidad o en contra de esta.

\section{Bibliografía}

Bueno, M.A. (2015). Y Del Principio De La Realidad En Racional the Role of the Pleasure Principle and the Reality Principle in the Construction of Rational Subjectivity. UNED Facultad de Filosofía, 35, 195-212. https://doi.org/https://doi.org/10.5944/endoxa.36.2015.14438

Fernández Poncela, Anna María. (2012). Psicología de masas, identidad social, epidemias y rumores: la influenza en México. Sociológica (México), 27(76), 189-230. Recuperado en 06 de julio de 2020, de http://www.scielo.org.mx/scielo.php?script=sci_arttext\&pid=S0187-

$01732012000200006 \& \operatorname{lng}=$ es\&tlng=es.

Freud, S. (1992). Sigmund Freud Obras completas XVIII, Más Allá del Principio de Placer, Psicología de las Masas y Análisis del Yo y Otras Obras. Obras Completas, (1920-1922) Tomo XVIII, Buenos Aires, Amorrortu editores. https://www.bibliopsi.org/docs/freud/18\%20-\%20Tomo\%20XVIII.pdf

Benbenaste, Narciso, Delfino, Gisela Isabel, \& Vitale, Nora Beatriz. (2006). La contribución de la psicología al concepto de poder. Universitas Psychologica, 5(2), 351-360. Retrieved July 06, 2020, from http://www.scielo.org.co/scielo.php?script=sci_arttext\&pid=S165792672006000200011\&lng=en\&tlng=es. 
Le Bon, G. (2004). Psicología de las masas. Buenos Aires, Omegalfa Consultado en: https://www.omegalfa.es/autores.php?letra=\&pagina=12\#

Marx. K. (1850): Las luchas de clases en Francia de 1848 a 1850. (n.d.). Retrieved May 2, 2020, from https://www.marxists.org/espanol/me/1850s/francia/francia1.htm

Marx, C., \& Engels, F. (2011). Manifiesto del Partido Comunista. México, Centro de Estudios Socialistas Carlos Marx, consultado en: https://centromarx.org/images/stories/PDF/manifiesto\%20comunista.pdf 